\title{
RELEVÂNCIA DO MODELO DE EMBREAGEM NO DESEMPENHO LONGITUDINAL DO VEÍCULO
}

\author{
Jony Javorski Eckert ${ }^{1}$, Fabio Mazzariol Santiciolli ${ }^{1}$, Eduardo dos Santos Costa $^{1}$, Arthur \\ Germano Cardoso ${ }^{1}$, Franco Giuseppe Dedini ${ }^{1}$ \\ ${ }^{1}$ Universidade Estadual de Campinas- Unicamp
}

javorski@fem.unicamp.br, fabio@fem.unicamp.br, eduardo.costa@fem.unicamp.br, arthurgcardoso@gmail.com, dedini@fem.unicamp.br

\section{RESUMO}

A embreagem transmite, por atrito, o torque do motor a combustão por meio de dois componentes denominados placa e volante, ligando o virabrequim do motor à caixa de redução. A interação entre placa e volante é controlada por meio do pedal de embreagem que, quando acionado, determina o distanciamento entre as partes, caracterizando o grau de acoplamento da embreagem. O acoplamento máximo ocorre quando o pedal é liberado. Nesta condição, uma mola pressiona a placa contra o volante.

A maioria dos modelos de dinâmica veicular longitudinal descrita pela literatura, despreza a influência da embreagem, assumindo que não haverá efeito adicional. Por este motivo, o objetivo deste trabalho é a comparação entre a dinâmica veicular longitudinal modelada convencionalmente com uma segunda modelagem, considerando o equacionamento analítico de uma embreagem. Finalmente, torna-se possível quantificar a relevância do modelo de embreagem para a análise longitudinal dinâmica. As simulações são executadas pelo MATLAB/Simulink ${ }^{\circledR}$, que interage com um modelo de bancada inercial multicorpos implementado em Adams ${ }^{\circledR}$.

\section{INTRODUÇÃO}

A dinâmica veicular é um ramo de estudo que analisa as interações entre veículo, condutor e ambiente. A literatura propõe a divisão da dinâmica veicular em três grandes áreas: longitudinal, vertical e lateral.

A dinâmica longitudinal é responsável pelo cálculo da potência requerida por um veículo para que este possa cumprir um determinado trajeto, estimando, por meio de equações, forças que atuam no sistema, como: a resistência aerodinâmica e a interação pneu-pista, assim como: fatores referentes ao ângulo de inclinação da pista e comportamento do motorista.

Os modelos de equacionamento, propostos pela maior parte da literatura sobre este tema, desprezam o efeito da embreagem, considerando que o motor está acoplado diretamente à caixa de câmbio. Entretanto, a embreagem é um componente fundamental no trem de potência por exercer influência significativa no torque transmitido do motor para a caixa redutora durante a troca de marchas, enquanto as rotações dos mesmos são acopladas. 
O objetivo deste trabalho é a modelagem do veículo por meio de simulações de duas formas distintas. Primeiramente, a dinâmica longitudinal será modelada conforme proposto pela literatura tradicional; em um segundo modelo, será adicionado o equacionamento englobando o sistema de embreagem, possibilitando assim um comparativo entre os modelos com base no consumo de combustível e no desempenho.

\section{EQUACIONAMETO DA DINAMICA LONGITUDINAL}

Neste trabalho será utilizada a metodologia de cálculo proposta por [1] onde a modelagem é baseada no somatório de forças atuantes na direção de deslocamento do veículo como mostra a Figura 1.

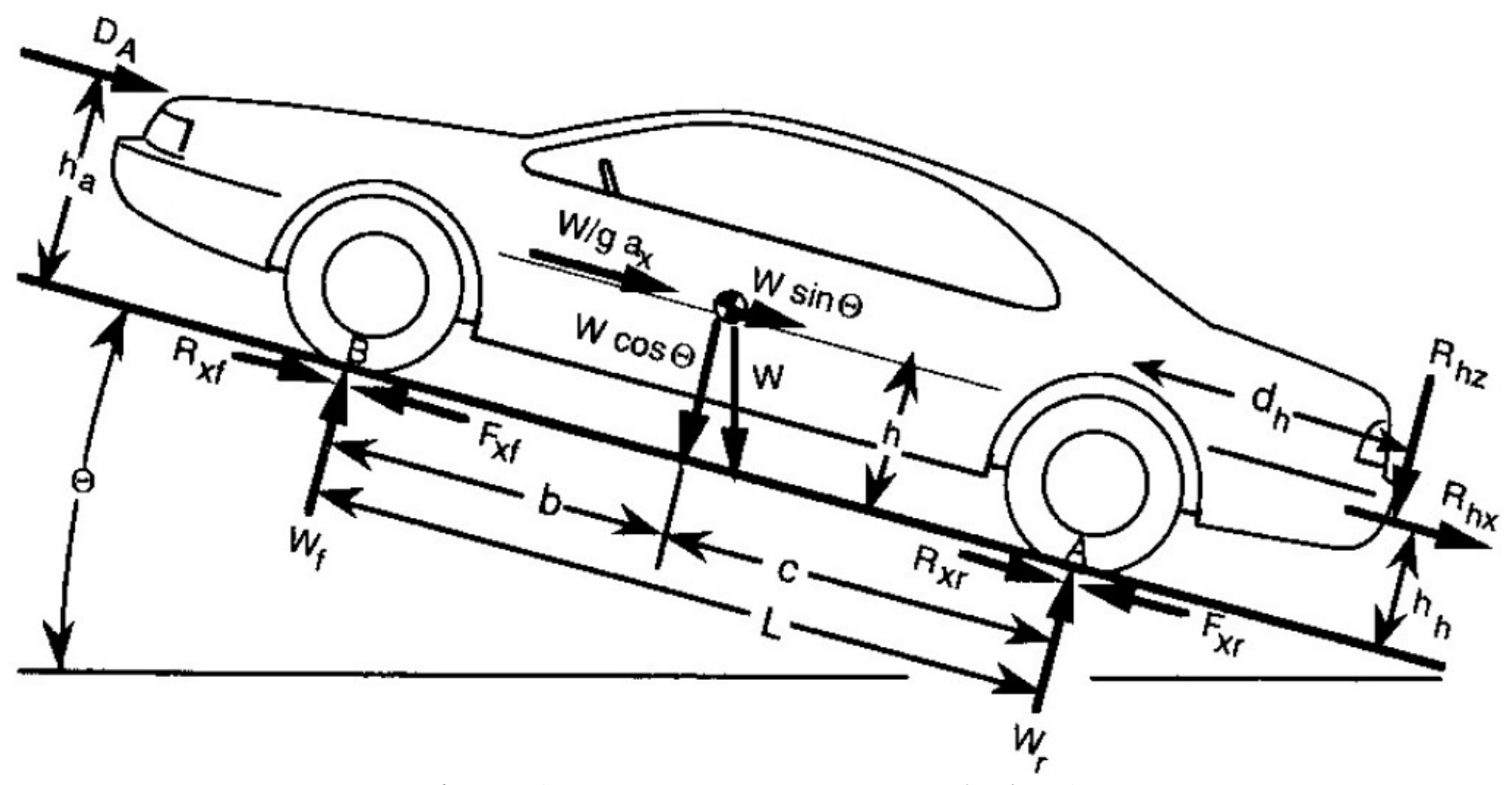

Figura 1- Forças que atuam no veículo [1].

\subsection{Carga Aerodinâmica}

A carga aerodinâmica $\left(D_{A}\right)$ é causada pela resistência imposta pelo ar na passagem do veículo, sendo que este efeito é proporcional ao quadrado da velocidade. Segundo [2] um veículo se locomovendo a uma velocidade específica gera uma força de resistência ao seu movimento. Esta força, denominada arrasto aerodinâmico, é resultante de dois componentes: força de arrasto e atrito superficial.

Devido à complexidade do escoamento do ar pelo exterior do veículo, o equacionamento desta carga é baseado em um termo empírico constante e denominado coeficiente de arrasto, como demonstrado na Equação 1.

$D_{A}=\frac{1}{2} \rho V^{2} C_{d} A$

Onde $\rho$ representa a densidade do ar em $\left[\mathrm{kg} / \mathrm{m}^{3}\right], V$ a velocidade do veículo em $[\mathrm{m} / \mathrm{s}]$, o termo $A$ se refere à área frontal do veículo e $C_{D}$ é o coeficiente de arrasto aerodinâmico. 


\subsection{Resistência ao rolamento}

Em baixas velocidades no pavimento rígido, a resistência ao rolamento $\left(R_{x}\right)$ é a força de resistência primária de movimento, causada basicamente pela deformação dos pneus, do pavimento e pelo fenômeno de adesão entre pneu e pista. Este trabalho, em particular, empregará pavimentos rígidos, tal como asfalto e concreto. Nestes casos, a rigidez do pavimento é muito superior à dos pneus e, deste modo, pode-se considerar a pista indeformável [1]. A Equação 2 expõe a formulação desta resistência.

$R_{x}=f_{r} W$

Onde $W$ é o peso do veículo em $[N]$ e $f_{r}$ representa o coeficiente de resistência ao rolamento calculado pela Equação 3 em função da velocidade do veículo.

$f_{r}=0,01\left(1+\frac{0,62 V}{100}\right)$

\subsection{Resistência à inclinação da pista}

Este termo se refere à decomposição da força peso resultante do ângulo de inclinação da pista. Em subidas, a componente da força peso atua retardando o movimento do veículo, e em uma situação de descida, a força peso auxilia o movimento.

1.4. Forças referentes à aceleração

A aceleração do veículo gera forças de resistência tanto pelo deslocamento longitudinal do veículo quanto pela inércia de rotação do powertrain. A força de tração disponível $\left(F_{x}\right)$ em função do torque do motor a combustão e da relação de transmissão é dada pela Equação 4:

$F_{x}=\frac{T_{e} N_{t f} \eta_{t f}}{r}-\left(\left(I_{e}+I_{t}\right) N_{t f}^{2}+I_{d} N_{f}^{2}+I_{w}\right) \frac{a_{x}}{r^{2}}$

Sendo:

- $\quad T_{e}=$ Torque disponível no motor a combustão

$[N m]$

- $\quad N_{t f}=$ Relação de transmissão total;

- $\eta_{t f}=$ Eficiência global do sistema de transmissão;

- $r$ = Raio externo do pneu

- $I_{e}=$ Inércia referente ao motor a combustão

- $I_{t}=$ Inércia da caixa redutora

- $I_{d}=$ Inércia do diferencial

- $I_{w}=$ Inércia das rodas, cubos e pneus

- $N_{f}=$ Relação de transmissão da caixa redutora;

- $a_{x}=$ Aceleração longitudinal do veículo

$[m]$

$\left[\mathrm{kgm}^{2}\right]$;

$\left[\mathrm{kgm}^{2}\right]$;

$\left[\mathrm{kgm}^{2}\right]$

$\left[\mathrm{kgm}^{2}\right]$;

$\left[m / s^{2}\right]$

O desempenho em aceleração do veículo é dado pela Equação 5:

$M a_{x}=F_{x}-R_{x}-D_{A}-W \operatorname{sen}(\theta)$ 
Onde $M$ representa a massa do veículo $[\mathrm{kg}]$ e $\theta$ a inclinação da pista $[\mathrm{rad}]$.

Unindo as equações 4 e 5 e isolando o termo referente ao torque do motor ( $\left.T_{e}\right)$ é possível estimar o torque necessário para movimentar o veículo em uma situação preestabelecida.

$T_{e}=\frac{\left(M a_{x}+\frac{\left(\left(I_{e}+I_{t}\right) N_{t f}{ }^{2}+I_{d} N_{f}^{2}+I_{w}\right) a_{x}}{r^{2}}+R_{x}+D_{A}+W \operatorname{sen}(\theta)\right) r}{N_{t f} \eta_{t f}}$

O máximo desempenho em aceleração longitudinal de um veículo motorizado é limitado pela potência do motor ou pelo limite de tração das rodas em contato com a pista. A velocidade do veículo determina qual limite prevalece: em baixas velocidades a tração nos pneus é o fator limite e em altas velocidades a potência disponível no motor é o fator limitante [1].

A força máxima transmissível no contato pneu-pista $\left(F_{\max }\right)$ é dada pela Equação 7 , considerando um modelo simplificado de diferencial bloqueado.

$F_{\max }=\frac{\mu \frac{W_{c}}{L}}{1+\frac{h}{L} \mu}$

Onde:

- $\quad \mu$ = Coeficiente de atrito pneu-pista;

- $W_{c}=$ Parcela da força peso atuante no eixo dianteiro $[N]$;

- $L=$ Distância entre eixos

$[m]$

- $h=$ Altura do centro de gravidade do veículo

$[m]$.

\section{SISTEMA DE TRANSMISSÃO DE POTÊNCIA}

O motor a combustão interna não é adequado para uma propulsão veicular direta, portanto, o mesmo requer um sistema de transmissão para fornecer ao veículo a força de tração que irá satisfazer a demanda de potencia nas condições operacionais [3].

O powertrain do veículo consiste de uma fonte de energia (motor a combustão ou elétrico), uma embreagem (transmissão manual) ou um conversor de torque (transmissão automática), a caixa de câmbio, o diferencial, o eixo de transmissão e as rodas motrizes [3]. O motor de combustão interna não pode operar abaixo de uma velocidade mínima (marcha lenta), portanto, o veículo não pode mover-se mais devagar do que a velocidade mínima enquanto o motor estiver conectado ao sistema de transmissão e consequentemente as rodas de tração. Ao iniciar e parar o movimento, o veículo precisa ter velocidades inferiores à velocidade minima do motor e a embreagem deve ser utilizada para compensar a diferença entre a menor velocidade de operação do motor e a velocidade do eixo de entrada de transmissão [4].

Esta embreagem transmite o torque do motor por meio de forças de atrito no eixo de entrada da transmissão, permitindo a completa separação e um rápido reacoplamento, sem solavancos do fluxo de torque em ambos os componentes [4]. 
A embreagem, ao desacoplar o motor a combustão do restante do powertrain, permite que o motor seja acionado sem o movimento do veículo, sendo este retirado do repouso sob controle em várias taxas de aceleração [5].

\section{MODELO EMBREAGEM}

Embreagens estão associadas com caixas de velocidades manuais e são normalmente operadas pelo condutor, ou seja, o motorista tem que alternar entre as relações de transmissão, sendo que estas possuem engrenagens de diferentes dimensões que permitem diferentes velocidades relativas entre o motor e as rodas do veículo [5].

A embreagem faz uso de fricção para transmitir a rotação do eixo de manivelas do motor para a caixa de redução do veículo. Quando o pedal de embreagem é liberado, a mola força a placa de embreagem contra o volante ligado ao virabrequim [6].

Quando um veículo que tem uma transmissão por engrenagems com um sistema de troca manual parte do repouso, ocorre um deslizamento entre o volante e a placa da embreagem e, portanto, a velocidade do veículo não está diretamente relacionada com a velocidade do motor, neste caso [3].

Durante o desacoplamento da caixa redutora, o torque gerado no motor não é transmitido a diante, mas conforme o contato entre os discos da embreagem é retomado, o torque volta a ser transmitido, gradualmente, por meio do escorregamento entre os discos da embreagem até que ocorra o total acoplamento do sistema.

No modelo usualmente adotado pela literatura, a rotação do motor é calculada em função da rotação da roda e da relação de transmissão escolhida a partir da faixa de velocidade do veículo no instante calculado. Com o modelo de embreagem, é possível calcular a rotação real do motor $\left(\omega_{E}\right)$ durante o processo de troca de marchas por meio da Equação 8.

$\omega_{E}=\omega_{o}+\dot{\omega}_{E} d t$

A aceleração do motor $\left(\dot{\omega}_{E}\right)$ é dada pela Equação 9

$I_{e} \dot{\omega}_{E}=T_{e}-T_{F R}-T_{C}$

Onde:

- $T_{e}=$ Torque do motor

$[N m]$

- $T_{F R}=$ Torque das perdas por fricção

$[\mathrm{Nm}]$

- $T_{C}=$ Torque de resistência

$[N m]$

- $I_{e}=$ Inércia do motor

- $d t=$ Intervalo de tempo de simulação

$\left[\mathrm{kgm}^{2}\right]$;

- $\omega_{o}=$ Rotação do motor no instante anterior

$[s]$

- $\omega_{E}=$ Rotação do motor

- $\dot{\omega}_{E}=$ Aceleração angular do motor

O torque máximo que a embreagem pode transferir para o veículo é, geralmente, de $10 \%$ a $20 \%$ acima do torque máximo do motor [7], sendo que o torque transmitido pela embreagem 
depende da posição do pedal da embreagem. Quando pressionado, o pedal da embreagem reduz a força normal entre a placa de embreagem e o volante, diminuindo a força de atrito e, como consequência, o torque transmissível [6].

O torque transmissível pela embreagem $\left(T_{C L}\right)$ é dado pela Equação 10 utilizada por [8].

$T_{C L}=\mu F_{n} n\left(\frac{2}{3}\right)\left(\frac{R_{o}^{3}-R_{i}^{3}}{R_{o}{ }^{2}-R_{i}^{2}}\right)$

Sendo:

- $\quad T_{C L}=$ Torque transmitido pela embreagem

$[N m]$

- $\mu$ = Coeficiente de atrito da embreagem

$[\mathrm{Nm}]$

- $F_{n}=$ Força normal aplicada no contato entre os discos

$[N]$;

- $n$ = Número de faces da embreagem;

- $R_{o}=$ Raio externo do disco da embreagem

$[m]$

- $R_{i}=$ Raio interno do disco da embreagem

$[m]$.

\section{SIMULAÇÃO DINÂMICA}

A simulação da dinâmica longitudinal é frequentemente usada para comparar a importância das características de equilíbrio de energia para veículos, sem a necessidade de construir protótipos que requerem tempo e alto custo [9].

Segundo [9], as equações físicas básicas do movimento longitudinal do veículo são fundamentais para entender as relações causa-efeito entre o motorista, veículo e solo. Algumas variáveis de entrada são:

- Ciclo de tráfego;

- Especificações do veículo (por exemplo: resistência de rolamento, resistência do ar, peso etc.);

- Especificações de componentes individuais (por exemplo: características de perda de desempenho da caixa de câmbio).

As simulações executadas neste trabalho foram feitas por meio do programa de análise dinâmica de multicorpos Adams ${ }^{\circledR}$ (Automatic Dynamic Analysis of Mechanical Systems), no qual está implementado o modelo veicular analisado. O controle das variáveis referentes à dinâmica longitudinal, conforme descrito anteriormente, é feito por meio da interface entre o Adams ${ }^{\circledR}$ e o MATLAB/Simulink ${ }^{\circledR}$.

O veículo simulado foi baseado em um Hatchback compacto equipado com motor 1.0L. O modelo implementado, foi idealizado com base numa bancada dinamométrica, para viabilizar futuras validações experimentais. Os efeitos do sistema de suspensão do veículo, foram desprezados com intuito de simplificar o modelo, da mesma forma que estes fatores são desconsiderados pela literatura vigente.

O modelo é composto por um conjunto de dois rolos que simulam a inércia referente ao deslocamento longitudinal, conforme descrito por [10], nos quais são apoiados quatro cilindros que representam as rodas do veículo que estão presas a um chassi com massa similar ao veículo analisado, como mostra a Figura 2. 


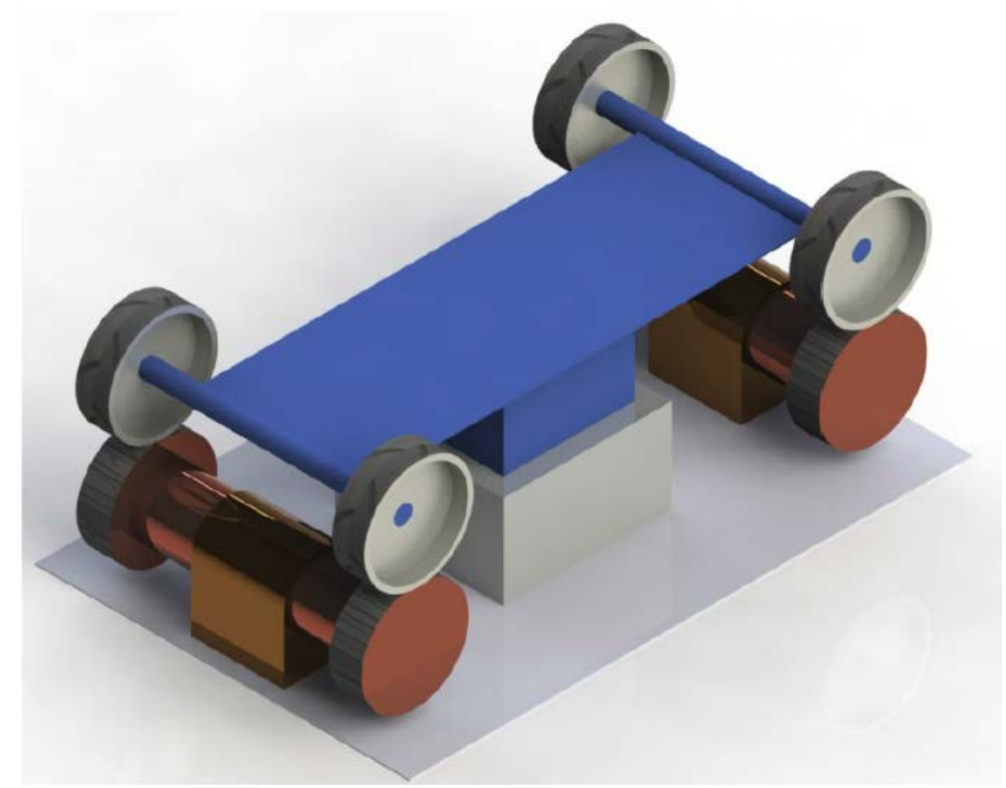

Figura 2- Modelo CAD para simulação

O modelo CAD foi posteriormente exportado para o Adams ${ }^{\circledR}$, onde foram criadas juntas de revolução apropriadas para permitir o movimento das rodas e das massas rotativas. Nestas rodas, foram aplicados torques referentes à potência fornecida pelo motor a combustão através do sistema de transmissão às rodas dianteiras, bem como os torques (nas quatro rodas) provenientes do sistema de freio. Nas massas rotativas, foi aplicado um torque referente às forças de resistência ao movimento.

No modelo, o chassi do veículo encontra-se conectado à base para impedir movimentação longitudinal, de forma que as rodas se mantenham alinhadas aos rolos. O movimento de rotação entre os rolos e as rodas é feito por meio de uma junta, transmitindo os momentos e rotações atuantes.

Para facilitar a aplicação das equações da dinâmica veicular, foi utilizada a interface do Adams $^{\circledR}$ com o Simulink ${ }^{\circledR}$, gerando-se um bloco com os dados do modelo dinâmico (conforme mostra a Figura 3).
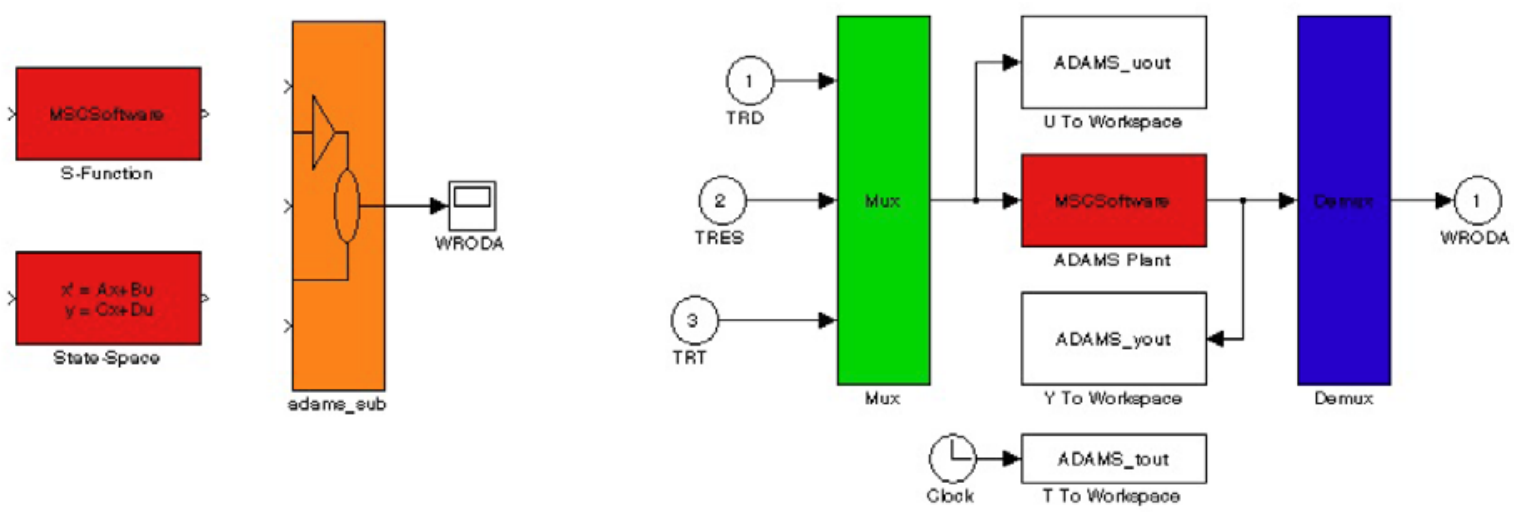

Figura 3 - Bloco gerado pelo Adams ${ }^{\circledR}$ 
O algoritmo programado em Simulink ${ }^{\circledR}$ trabalha junto com o solver do Adams ${ }^{\circledR}$. O Simulink ${ }^{\circledR}$ fornece para o Adams ${ }^{\circledR}$ os valores de torque a serem aplicados nas rodas e nas massas rotativas e o Adams ${ }^{\circledR}$ gera como resposta a velocidade angular das rodas, a qual realimenta o algoritmo do Simulink ${ }^{\circledR}$ para que este recalcule o torque requerido conforme a nova demanda.

\section{CICLOS PADRÃO DE CONDUÇÃO}

O comportamento do motorista será representado pelo cálculo da aceleração necessária para o veículo atingir a velocidade requerida num determinado instante. Como o interfaceamento entre o Simulink ${ }^{\circledR}$ e o Adams ${ }^{\circledR}$ é implementado em passos temporais fixos, a aceleração requerida é calculada pela diferença entre a velocidade requerida e a velocidade atual dividida pelo intervalo de tempo de simulação.

Com o intuito de estabelecer um parâmetro de comparação, foram utilizados ciclos padrão de velocidades para determinar o comportamento do veículo, de forma que o equacionamento calcule a potência necessária para que o veículo execute o perfil de velocidade requerido pelo ciclo pré-estabelecido.

Um ciclo de condução, representa a maneira como o veículo é conduzido durante uma viagem e as características do tráfego. No caso mais simples, o mesmo é definido como uma sequência de velocidades do veículo e de graus de inclinações da estrada [11]. Estes ciclos de condução são projetados para representar as condições de condução urbana e rodoviária, e reproduzir medidas de velocidade do veículo em estradas reais [12].

Nas simulações, foi utilizado o perfil de velocidade da norma brasileira ciclo urbano 6601 (Figura 4) que tem como características: distância total de $12 \mathrm{~km}$, velocidade média de 32 $\mathrm{km} / \mathrm{h}$ e velocidade máxima de $91,2 \mathrm{~km} / \mathrm{h}$. O veículo permanece parado durante $17,2 \%$ do tempo e o ciclo não inclui aclives e declives.

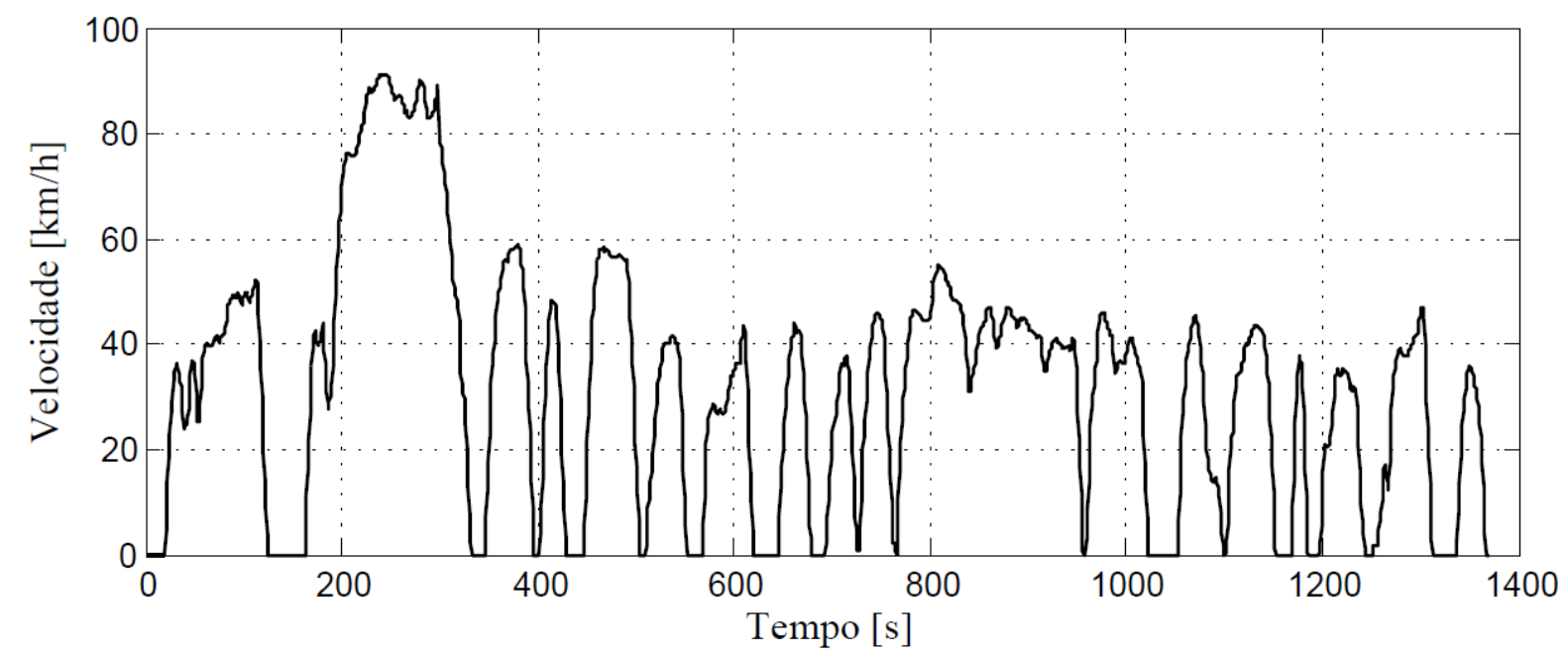

Figura 4 - Perfil de velocidades NBR6601

Devido ao perfil de velocidades da norma brasileira para ciclos rodoviários NBR7024 apresentar um longo trecho de alta velocidade, no qual não ocorrem mudanças na relação de transmissão, optou-se por utilizar como segunda opção para análise o ciclo US06 (Figura 5). 
O US06 complementa o ciclo de teste americano FTP-75 por representar velocidades e acelerações elevadas. Este ciclo representa um percurso de 12,8 $\mathrm{km}$, com velocidade média de $77,9 \mathrm{~km} / \mathrm{h}$, velocidade máxima de $129,2 \mathrm{~km} / \mathrm{h}$ e duração de 596 segundos. Assim, este ciclo possibilita uma melhor análise do desempenho do veículo em uma condição de aceleração, para avaliação do funcionamento do modelo proposto em uma condição crítica de operação.

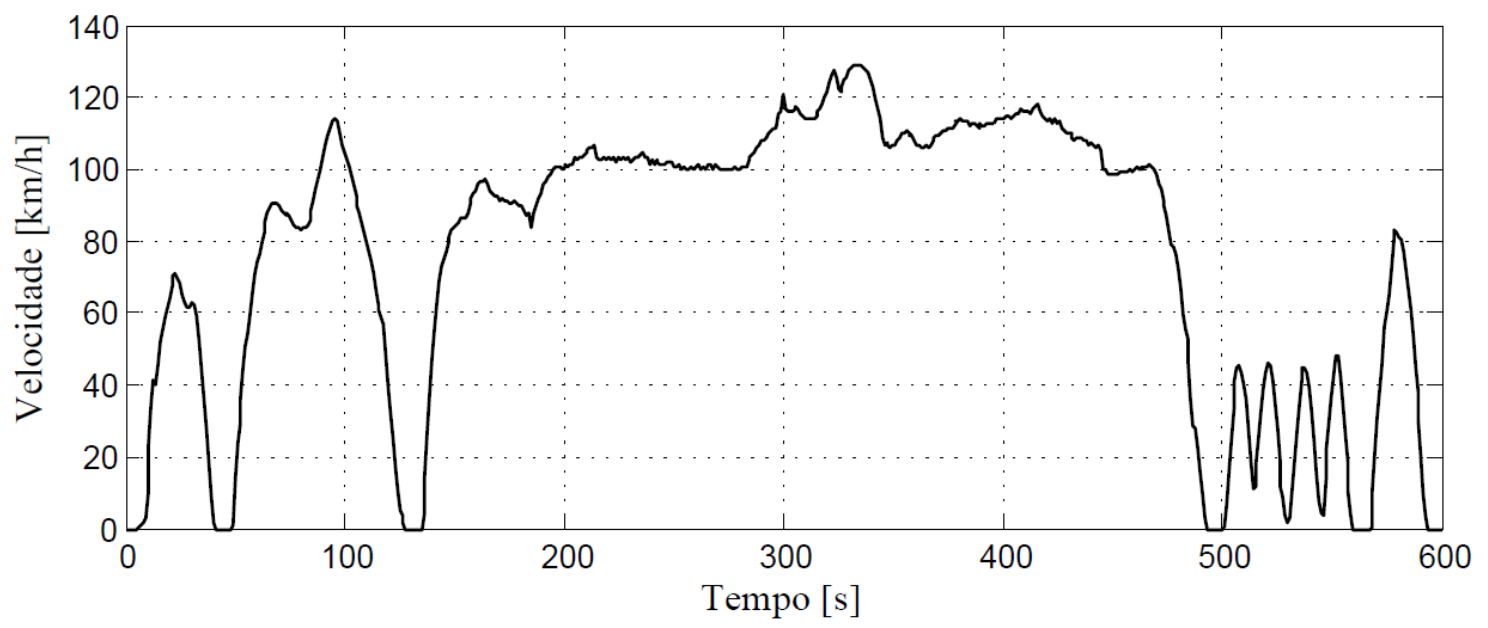

Figura 5- Perfil de velocidades US06

\section{CURVAS DE TORQUE E MAPA DE CONSUMO DO MOTOR A COMBUSTÃO}

O modelo simulado leva em conta as curvas de torque do motor a combustão (Figura 6), sendo o torque requerido pelo equacionamento descrito anteriormente, comparado com o torque disponível no motor em função da rotação e porcentagem de aceleração. Caso o torque requerido exceda o máximo torque disponível, ocorrerá perda de desempenho.

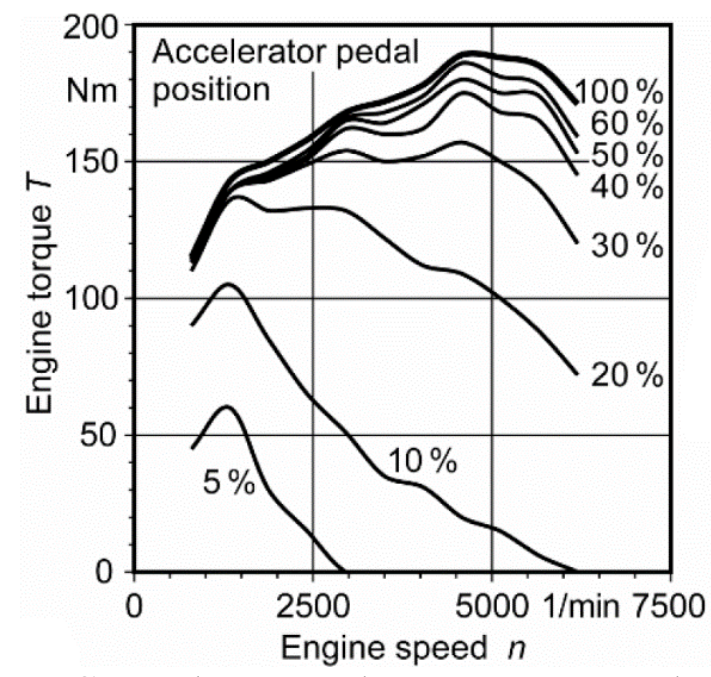

Figura 6 - Curva de torque de um motor a combustão [4].

O mapa de consumo de combustível (Figura 7) mostra as regiões de melhor eficiência do motor a combustão em função da rotação e do torque fornecido, de forma a permitir o cálculo do consumo a cada instante de tempo simulado. 
O mapa de consumo utilizado nas simulações foi baseado em um veículo com motor 1.0L movido somente a gasolina.

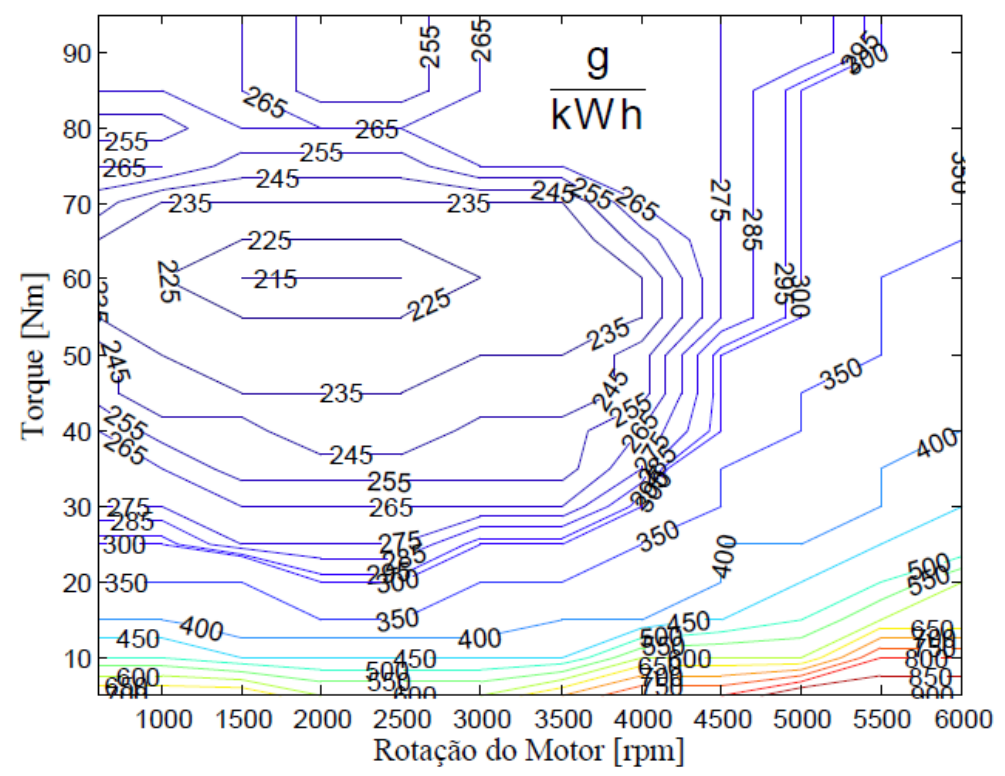

Figura 7 - Mapa de consumo de combustível do motor a combustão [13].

O consumo de combustível $\left(C_{l}\right)$ é calculado pela Equação 12 em função do consumo especifico $\left(C_{e}\right)$ obtido do mapa de consumo, da potência do motor $(P o t)$, intervalo de tempo $(d t)$ e massa especifica do combustível $\left(\rho_{c}\right)$.

$C_{l}=C_{e} \frac{P o t d t}{\rho_{c}}$

O mapa de consumo também possibilita a avaliação dos pontos para troca de marcha, mantendo o motor a combustão funcionando nas regiões de menor consumo. Neste trabalho, foi utilizada a estratégia de troca de marchas recomendada por [14].

\section{CORRELAÇÃO LINEAR}

Para avaliar a diferença entre os resultados apresentados, foi utilizada a correlação linear entre o perfil de velocidade do ciclo padrão adotado e o perfil de velocidade gerado pelo modelo. $\mathrm{O}$ coeficiente de correlação $r$ é uma medida numérica da intensidade da relação linear entre duas variáveis. O termo $r^{2}$ representa o quadrado do coeficiente de correlação, denominado coeficiente de determinação, e consiste na soma dos quadrados dos erros de previsão obtidos (como mostra a Equação 14).

$r^{2}=\frac{\left(\Sigma\left(x_{i}-\bar{x}\right)\left(y_{i}-\bar{y}\right)\right)^{2}}{\Sigma\left(x_{i}-\bar{x}\right)^{2} \Sigma\left(y_{i}-\bar{y}\right)^{2}}$

O $r^{2}$ da regressão mede a proporção da variabilidade de uma curva em função da outra e, portanto, é uma função direta da correlação entre as variáveis, mostrando o percentual da variância de uma das variáveis a partir do valor da outra. Um valor de $r^{2}$ muito próximo de 1 indica uma forte relação entre as duas variáveis. 


\section{DADOS PARA SIMULAÇÃO}

Os parâmetros geométricos utilizados nas simulações foram obtidos com base em um veículo comercializado em território nacional do tipo Hatchback compacto equipado com motor 1.0L, e caixa redutora com cinco relações de transmissão, conforme mostra a Tabela 1.

Tabela 1- Parâmetros do veículo.

\begin{tabular}{|c|c|c|c|c|c|c|}
\hline \multirow{2}{*}{ Componentes } & \multirow{2}{*}{ Unidade } & \multicolumn{5}{|c|}{ Marcha } \\
\hline & & $1^{\mathrm{a}}$ & $2^{\mathrm{a}}$ & $3^{\mathrm{a}}$ & $4^{\mathrm{a}}$ & $5^{\mathrm{a}}$ \\
\hline Inércia rotacional do motor & $\mathrm{kgm}^{2}$ & \multicolumn{5}{|c|}{0,1367} \\
\hline Inércia rotacional transmissão & $\mathrm{kgm}^{2}$ & 0,0017 & 0,0022 & 0,0029 & 0,0039 & 0,0054 \\
\hline Relação de transmissão & - & 4,27 & 2,35 & 1,48 & 1,05 & 0,8 \\
\hline Inércia rotacional do diferencial & $\mathrm{kgm}^{2}$ & \multicolumn{5}{|c|}{$9,22 \mathrm{E}-04$} \\
\hline Relação de transmissão do diferencial & - & \multicolumn{5}{|c|}{4,87} \\
\hline Inércia rotacional Rodas+Pneus & $\mathrm{kgm}^{2}$ & \multicolumn{5}{|c|}{2} \\
\hline Massa do veículo & $\mathrm{kg}$ & \multicolumn{5}{|c|}{980} \\
\hline Pneus & - & \multicolumn{5}{|c|}{$175 / 70 \mathrm{R} 13$} \\
\hline
\end{tabular}

Os dados referentes ao modelo de embreagem foram obtidos de [15], conforme mostra a Tabela 2.

Tabela 2 - Dados da embreagem

\begin{tabular}{|l|c|}
\hline \hline \multicolumn{2}{|c|}{ Dados da Embreagem } \\
\hline \hline Raio interno $R_{i}$ & $67 \mathrm{~mm}$ \\
\hline Raio externo $R_{o}$ & $95 \mathrm{~mm}$ \\
\hline Número de faces & 2 \\
\hline Coeficiente de atrito & 0,27 \\
\hline \hline
\end{tabular}

A força normal, aplicada na embreagem, é calculada conforme proposto por [15], baseada em um método gráfico que estima a força aplicada em função da posição do pedal de embreagem, da deformação da estrutura da embreagem e da força da mola que mantém o conjunto acoplado.

A simulação do comportamento do motorista no modelo é dada pelo acionamento do pedal de embreagem, considerando um tempo de 1,5 segundos para troca de marcha. O gráfico da Figura 8 demonstra os deslocamentos dos dedos da embreagem em função da posição do pedal de acionamento. Em função da posição dos dedos é possível identificar o deslocamento da placa, conforme mostra a Figura 9.

Durante os primeiros 0,5 segundos destinados ao desacoplamento do sistema de transmissão, o pedal da embreagem é levado da posição de repouso (sistema acoplado) ao fim de curso (sistema totalmente desacoplado). 


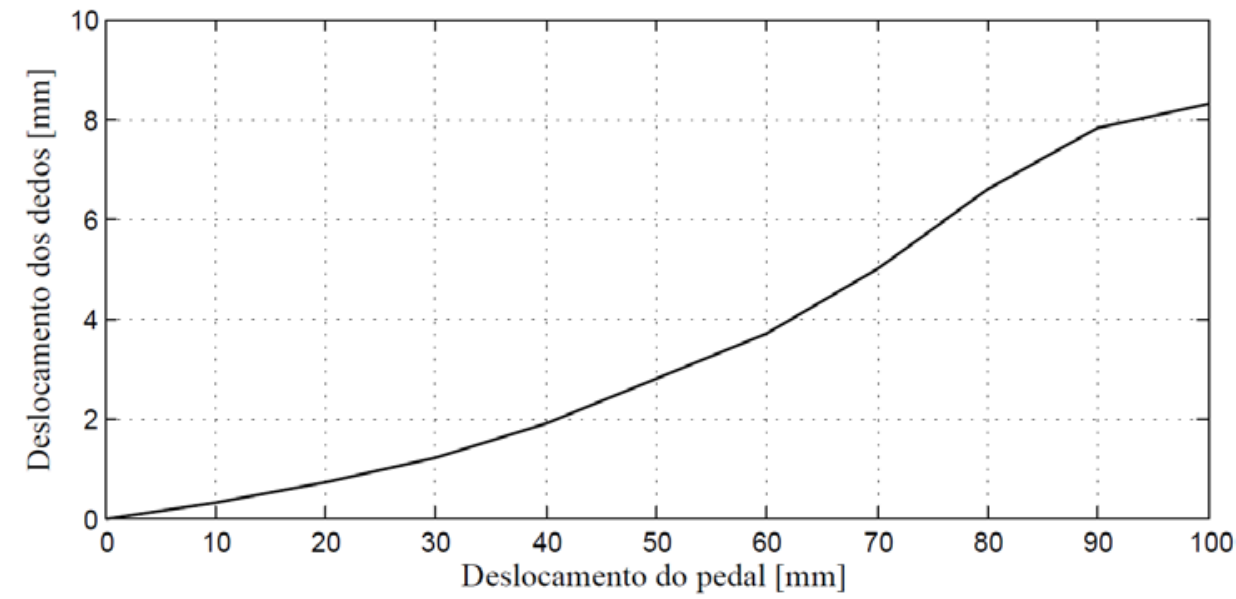

Figura 8- Deslocamento dos dedos da embreagem em função do deslocamento do pedal

Neste momento ocorre a mudança de marcha, o motor a combustão encontra-se completamente desacoplado do sistema de transmissão, ou seja, o mesmo não transmite torque para o sistema e também não é desacelerado pelo torque de resistência.

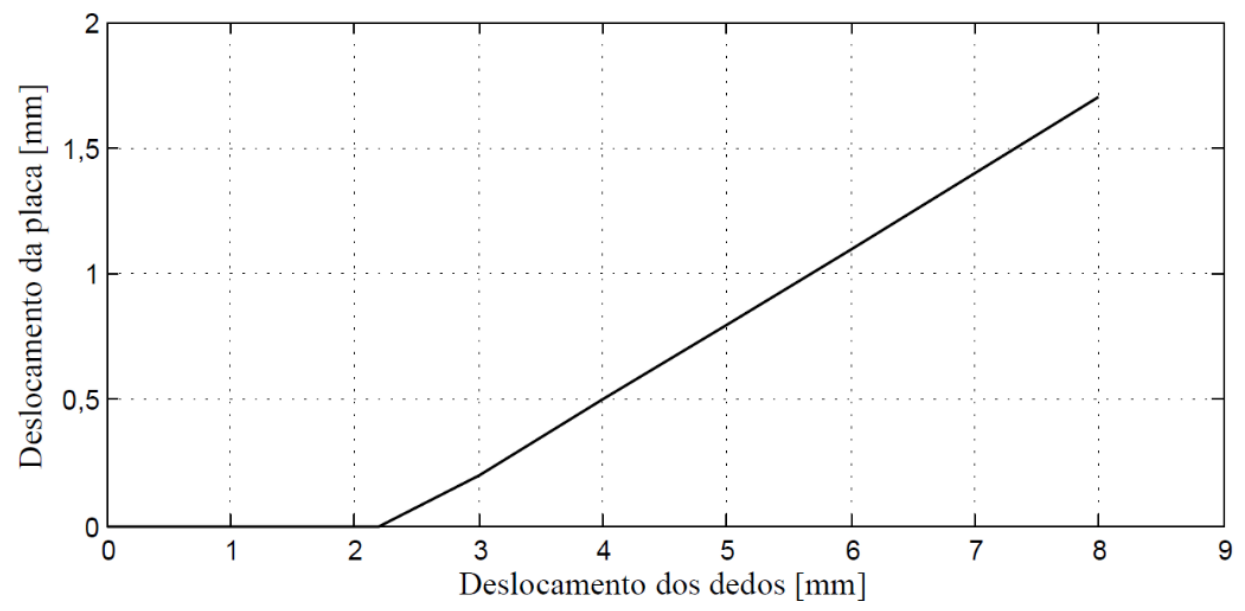

Figura 9 - Deslocamento da placa em função do deslocamento dos dedos da embreagem

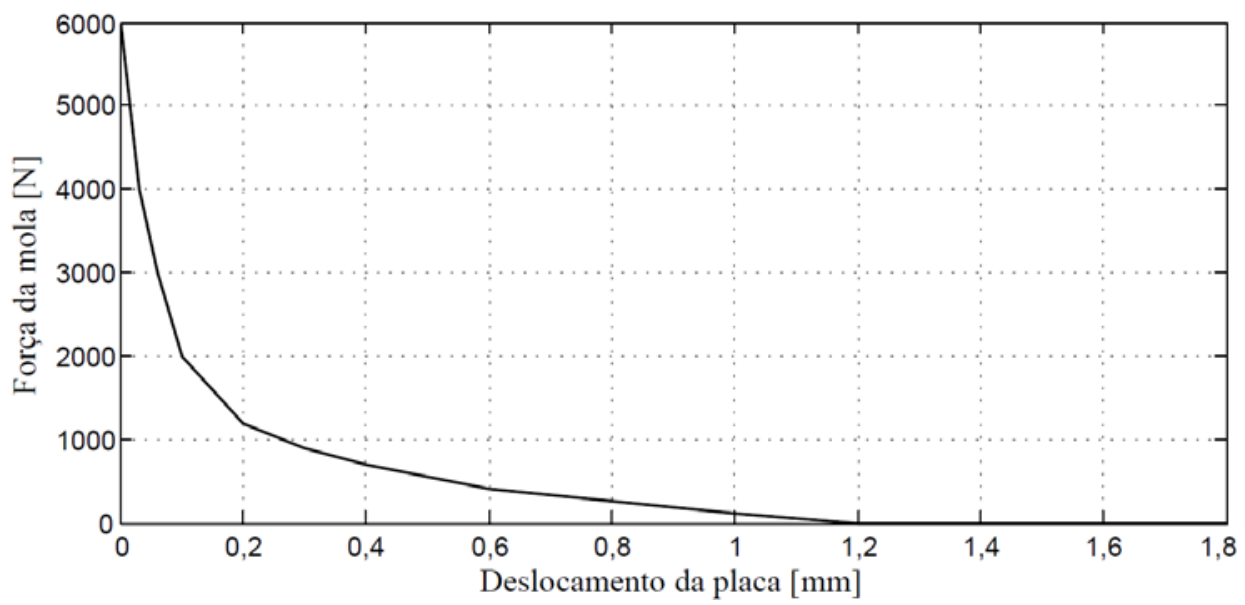

Figura 10 - Força normal aplicado pela mola em função do deslocamento da placa 
No restante do tempo, a posição do pedal retorna gradualmente da posição de fim de curso para a posição inicial, aumentando o torque transmitido entre o motor e a caixa redutora até a condição de total acoplamento.

Na condição intermediária, ocorre escorregamento entre o disco da embreagem, a placa e o volante. Nesta situação, atua a Equação 10, que permite estimar o torque transmitido em função da força aplicada. Esta equação é função do deslocamento da placa, como pode ser visto na Figura 10.

\section{RESULTADOS}

Primeiramente, foi simulado o modelo conforme descrito na literatura, sendo desconsiderado o efeito da embreagem. O ciclo escolhido para a análise inicial foi o ciclo urbano brasileiro NBR6601.

Em sequência, foi simulado o modelo modificado, com o acréscimo da embreagem conforme descrito anteriormente. As correlações entre o perfil de velocidades proposto pela norma e os resultados encontrados pelas simulações estão na Figura 11.

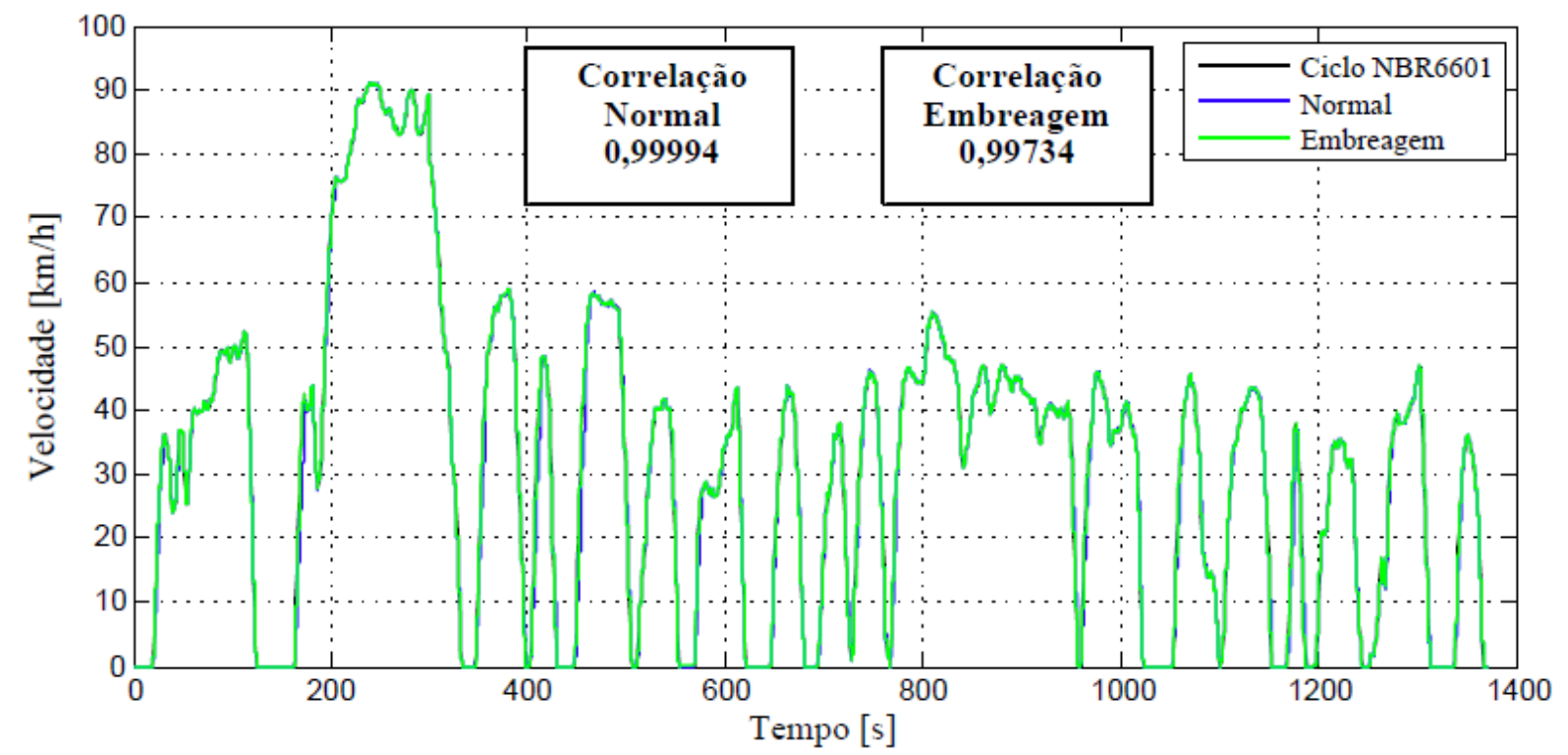

Figura 11 - Correlação entre o ciclo NBR6601 e os modelos simulados

A princípio, as curvas são idênticas, o que se deve a escala de tempo ser maior que a escala de velocidades. Reduzindo-se a área de análise em uma porção menor de tempo é possível visualizar as diferenças entre os resultados obtidos pelos modelos simulados.

A diferença entre as correlações ocorre apenas na terceira casa decimal devido ao algoritmo da simulação sempre aproximar-se do resultado do ciclo padrão, portanto, as curvas do perfil de velocidades da norma e da simulação são próximas entre si, gerando correlações sempre próximas de 1.

O fato das duas correlações serem próximas de 1 não indica que não há diferenças entre os resultados apresentados. A Figura 12 ilustra a diferença entre os métodos. 
Na Figura 12, pode-se observar claramente que o modelo que leva em consideração a embreagem, apresenta desempenho inferior ao modelo proposto pela literatura. O motivo está relacionado à redução e interrupção de fornecimento de torque para o modelo Adams ${ }^{\circledR}$ durante o tempo de troca de marcha, sendo necessária uma maior aceleração para retomar a velocidade do ciclo, o que resulta num maior consumo de combustível como pode ser visto na Figura 13.

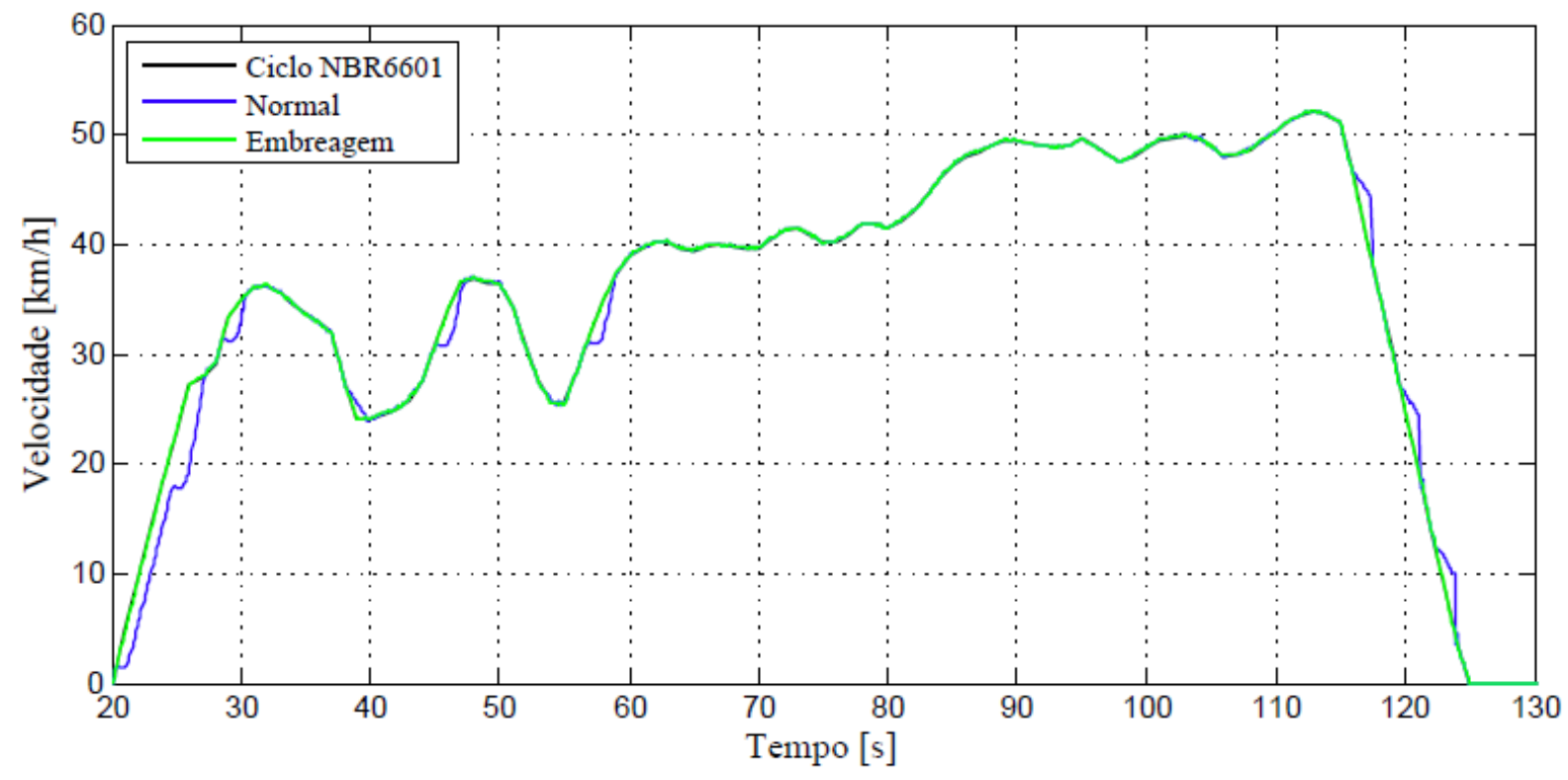

Figura 12 - Diferença entre os modelos simulados NBR6601

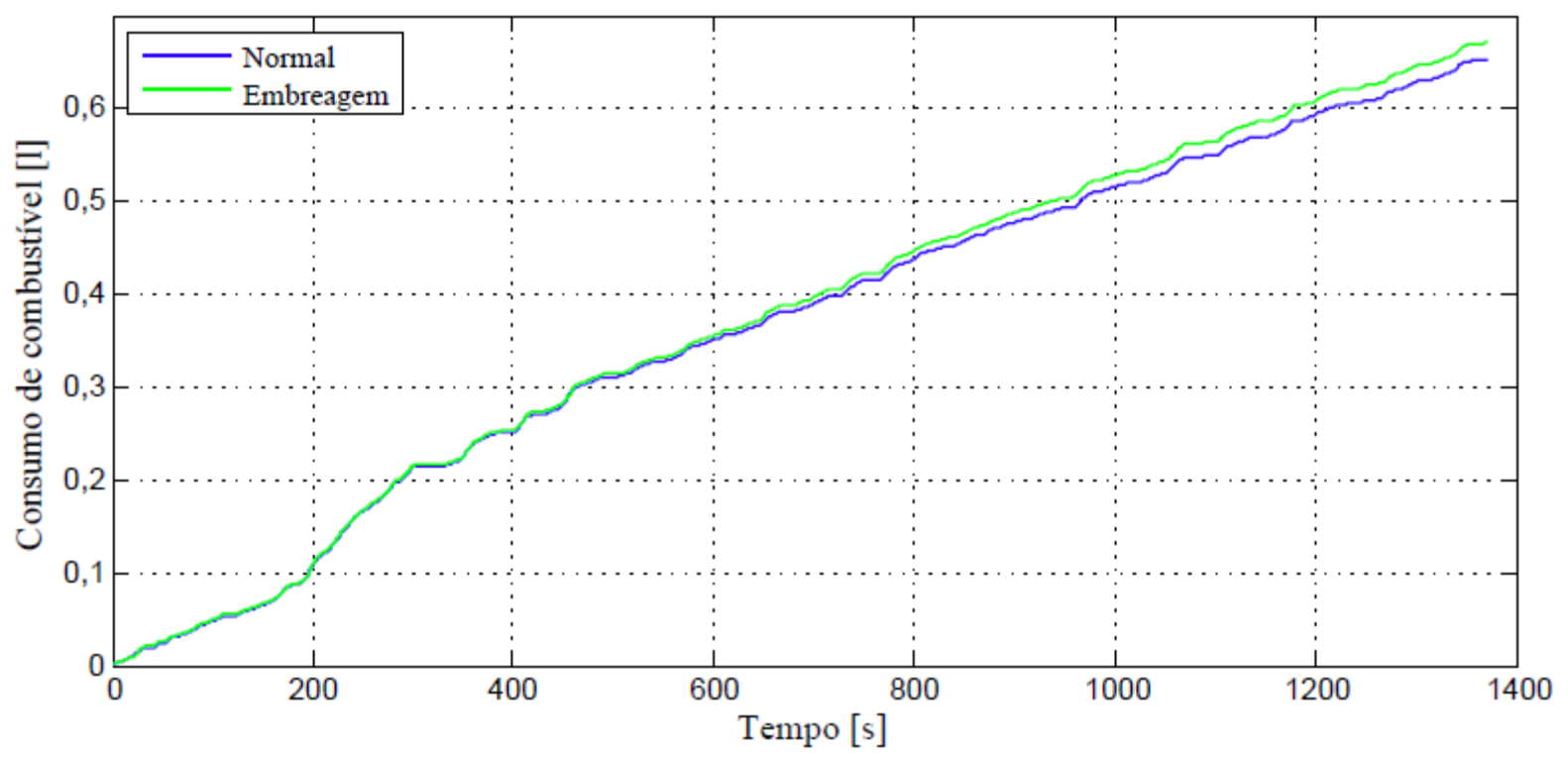

Figura 13 - Consumo de combustível nos modelos simulados NBR6601.

O modelo que considera o efeito da embreagem apresentou consumo de $670 \mathrm{ml}$ de combustível, o que resultou numa média de consumo de $17,67 \mathrm{~km} / \mathrm{l}$ e o modelo que despreza o efeito da embreagem apresentou um consumo de $653 \mathrm{ml}$, gerando uma média de 18,36 $\mathrm{km} / \mathrm{l}$. 
Pela diferença obtida no resultado de consumo de combustível, pode-se afirmar que a embreagem é um fator importante no cálculo da dinâmica longitudinal do veículo, por impactar diretamente o regime de funcionamento do motor a combustão, o desempenho em aceleração do veículo, e consequentemente, o consumo de combustível.

Para avaliar o modelo em uma situação mais crítica de alta aceleração, foram feitas simulações com o ciclo US06 e as correlações encontradas são mostradas na Figura 14.

Nas simulações executas no ciclo US06, o veículo não consegue cumprir o perfil de velocidades nas regiões de alta aceleração, pois o motor a combustão não fornece potência suficiente para executar o ciclo e mesmo com 100\% de aceleração disponível, o veículo simulado não atende à demanda de potência do ciclo simulado.

Este comportamento é mais evidente no modelo que considera a embreagem, pois existe uma redução no torque transmitido às rodas durante o processo de troca de marcha, gerando uma redução no desempenho (como mostra a Figura 15).

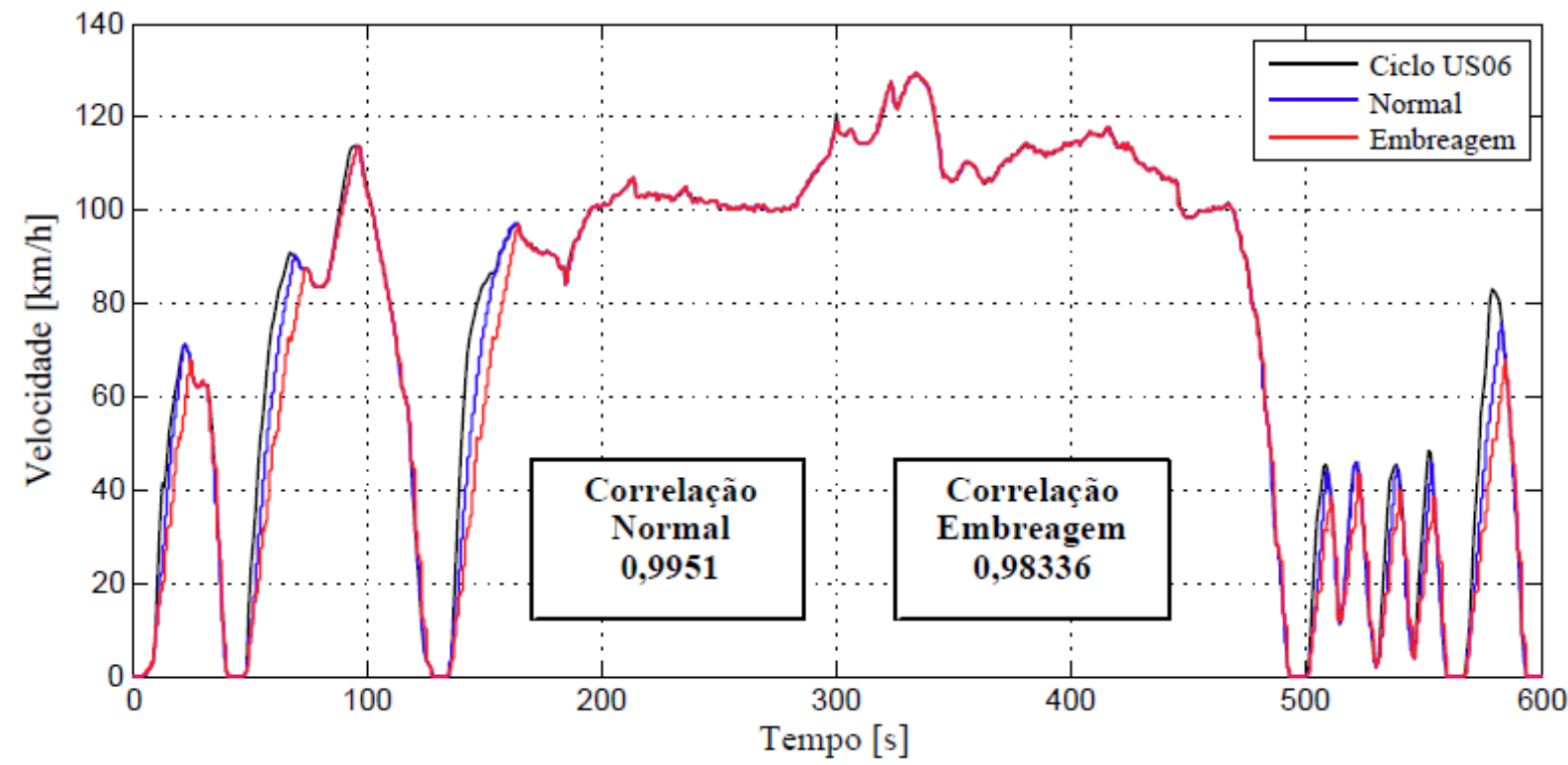

Figura 14 - Correlação entre o ciclo US06 e os modelos simulados

Outro fator limitante no desempenho do veículo neste ciclo é a força transmissível no contato pneu-pista. Deste modo, nas áreas de alta aceleração, nem toda a potência disponível é transmitida devido à limitação imposta pelo atrito no contato.

Quanto mais alta é a aceleração, mais o veículo tende a transferir carga para o eixo traseiro, reduzindo a parcela da força normal aplicada sobre as rodas dianteiras responsáveis pela tração e, consequentemente reduzindo a capacidade de transmissão de força do pneu para a pista sem que haja escorregamento.

No ciclo NBR6601, após a troca de marcha, o veículo simulado aumenta a aceleração para compensar a redução de velocidade gerada pelo desacoplamento da embreagem. Isto ocorre devido às acelerações moderadas contidas neste ciclo. 


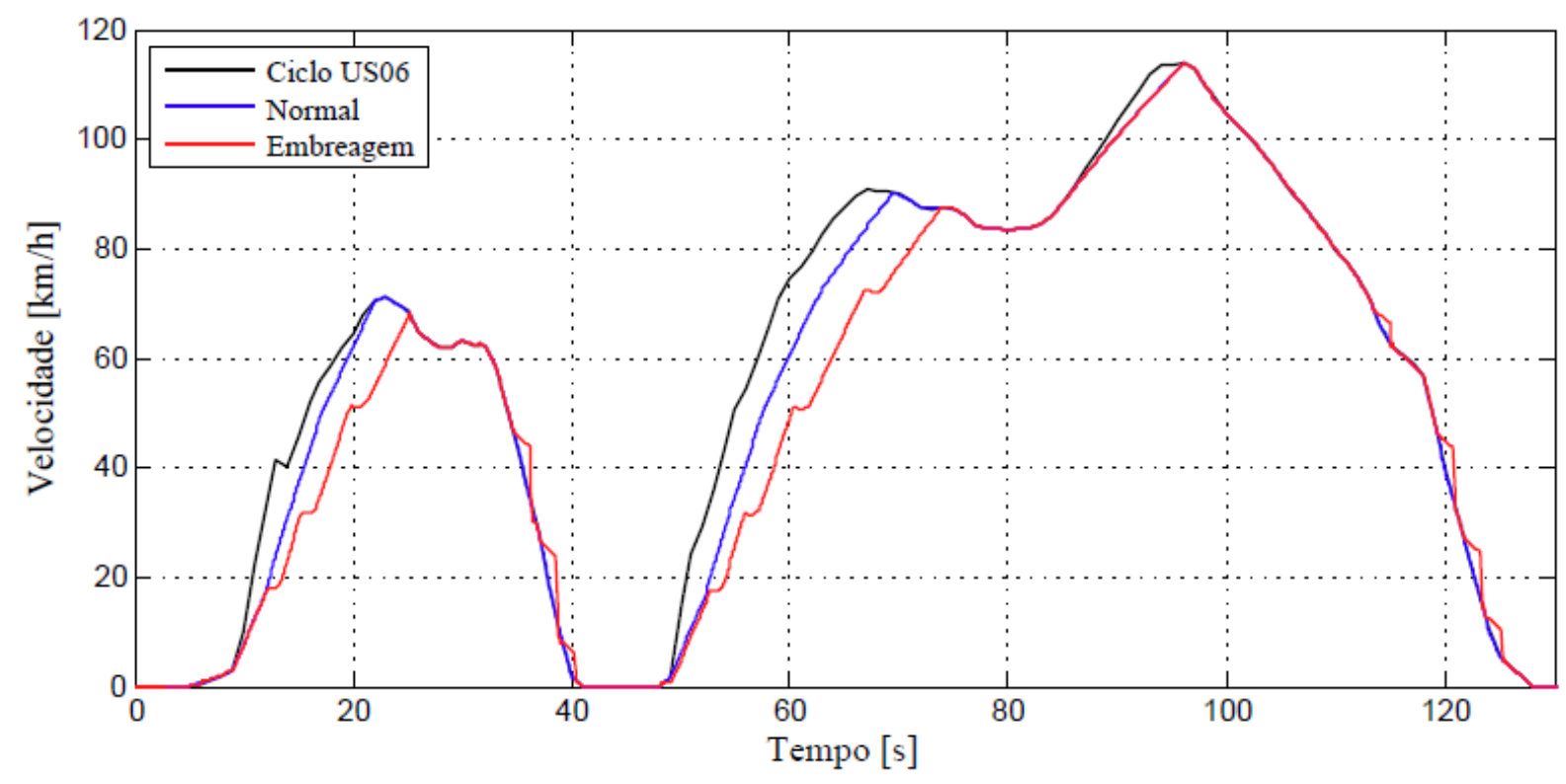

Figura 15 - Diferença entre os modelos simulados US06

No ciclo US06 o veículo encontra-se numa situação de máxima aceleração e não existe potência excedente para compensar a redução de velocidade. Na Figura 15 este fenômeno pode ser observado, sendo que a cada mudança de relação de transmissão ocorre uma redução no desempenho do veículo.

A diferença no consumo de combustível está descrita na Figura 16.

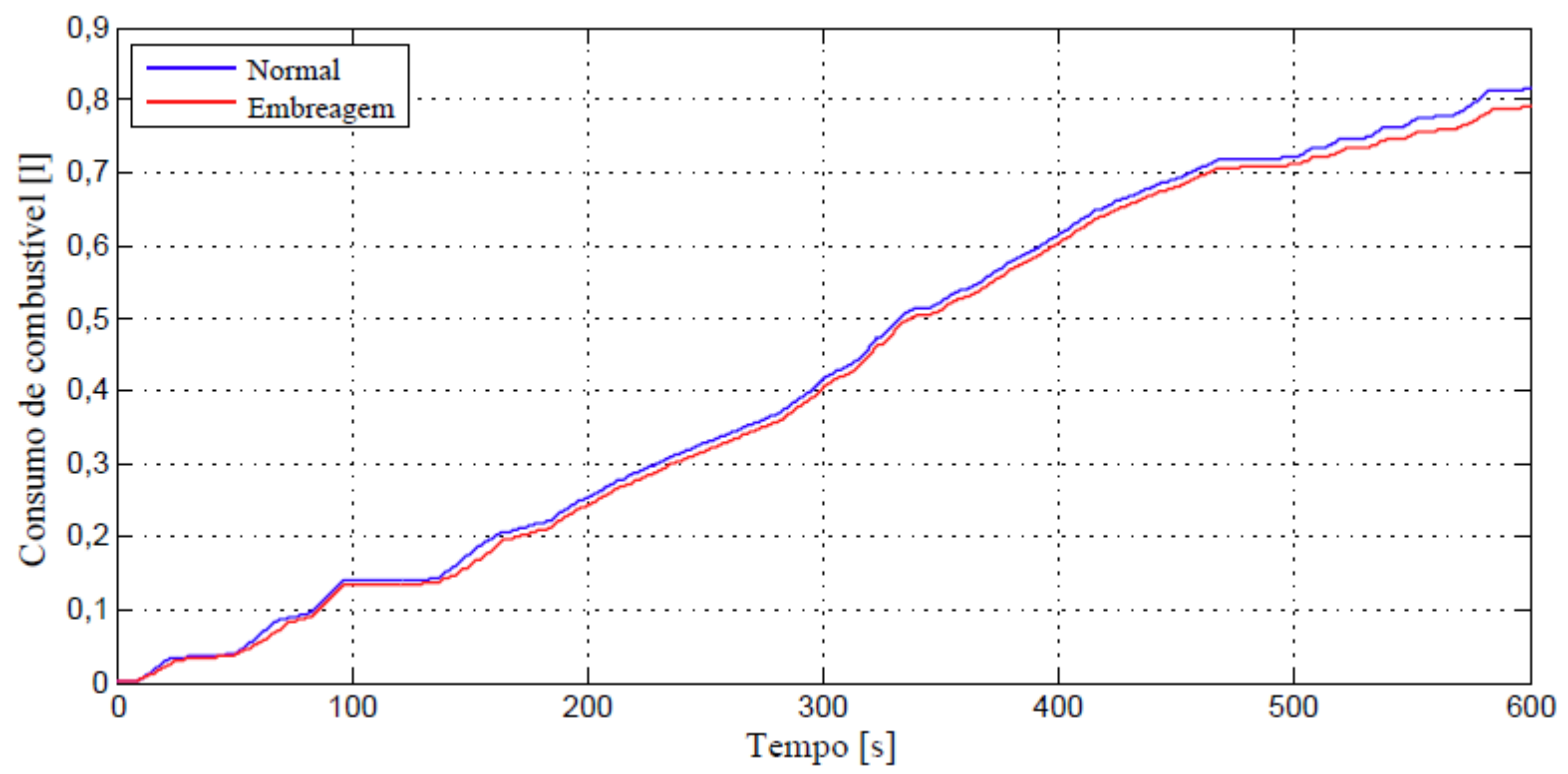

Figura 16 - Consumo de combustível nos modelos simulados US06

O modelo que considera a embreagem apresentou consumo de $791 \mathrm{ml}$ de combustível, o que corresponde a uma média de consumo de $15,61 \mathrm{~km} / \mathrm{l}$, enquanto o modelo que despreza os efeitos da embreagem apresentou um consumo de $816 \mathrm{ml}$ que representam uma média de consumo de 15,44 km/l. 
Neste caso, ocorreu uma inversão no consumo de combustível, e o modelo que considerou o fator embreagem foi mais econômico que o modelo convencional. Causa: os dois modelos estão trabalhando por longos períodos em $100 \%$ de aceleração, reduzindo-se os efeitos de compensação de aceleração após a troca de marcha, como ocorre no ciclo NBR6601. Este fator que diferencia o consumo de combustível nestas condições.

Também pode-se observar que o modelo que engloba a embreagem está, em grande parte do ciclo, em velocidade inferior ao outro modelo. Isto é, percorre uma distância inferior ao modelo normal, mesmo mantendo o regime de 100\% de aceleração.

Com os resultados apresentados pelas simulações é possível afirmar que a embreagem representa uma influência significativa no comportamento dinâmico do sistema veicular, exercendo influencia no desempenho em aceleração, bem como no consumo de combustível.

\section{CONCLUSÃO}

Neste trabalho, foi avaliada a influência da embreagem no cálculo da dinâmica longitudinal em um veículo. Os resultados foram obtidos por meio de simulações realizadas em programa de análise dinâmica de multicorpos Adams ${ }^{\circledR}$ conjuntamente com o Simulink/Matlab ${ }^{\circledR}$.

A metodologia de cálculo utilizada foi a descrita no livro Fundamentals of Vehicle Dynamics levando em conta as inércias do sistema de transmissão e fatores geométricos de um Hatchback compacto, equipado com motor 1.0L e um sistema de redução com cinco relações de transmissão.

As simulações consideraram os perfis de velocidade propostos pela norma brasileira de ciclo urbano MBR6601 e pelo complemento da norma americana FTP-75 (ciclo US06), de forma a criar um comportamento do motorista.

Pode-se observar que, com o acréscimo da embreagem na simulação, ocorre uma redução no desempenho do veículo no momento da troca de marchas devido ao desacoplamento do motor a combustão do restante do sistema de transmissão, gerando uma redução de velocidade devido à redução/interrupção da transmissão de torque.

No ciclo urbano brasileiro NBR6601 esta redução de velocidade é compensada com o aumento da aceleração do veículo após a mudança na relação de transmissão, sendo isto possível, pois neste ciclo as acelerações são moderadas e há potência excedente no veículo.

No ciclo americano US06, onde existem longos trechos de alta aceleração e é requerida a potência máxima do veículo, ocorre uma perda de desempenho a cada mudança de relação de transmissão, pois não existe potência excedente para compensação após a troca de marcha.

O consumo de combustível estimado é alterado significativamente no ciclo urbano NBR6601, devido ao aumento da potência requerida após a troca de relação de transmissão para compensar o período de transmissão parcial ou interrupção de torque. 
No ciclo US06, o consumo entre os modelos foi mais próximo, sendo o modelo que engloba a embreagem mais eficiente pelo fato de percorrer uma distância menor e ambos permanecerem em aceleração máxima por longos períodos de tempo.

Por último, conclui-se que a embreagem é um componente fundamental do powertrain do veículo, portanto seu comportamento dinâmico não deve ser desprezado no cálculo da dinâmica longitudinal, pois gera alteração no desempenho em aceleração e no consumo de combustível, de modo a aproximar a simulação ao comportamento real do veículo.

\section{AGRADECIMENTOS}

Os autores agradecem ao CNPq, CPFL, ANEEL e a Schaeffler pelo apoio financeiro.

\section{REFERÊNCIAS}

[1] GILLESPIE, T.D. Fundamentals of Vehicle Dynamics. SAE International, 1 ed., 1992

[2] EHSANI, M.; GAO, Y. e EMADI, A. Modern electric, hybrid electric, and fuel cell vehicles: fundamentals, theory, and design. CRC, 2009.

[3] WONG, Jo Yung. Theory of ground vehicles. Wiley-Interscience, 2001

[4] LECHNER, Gisbert; NAUNHEIMER, Harald; RYBORZ, Joachim. Automotive transmissions: fundamentals, selection, design and application. Springer, 1999

[5] CROLLA, David A. (Ed.). Automotive engineering: powertrain, chassis system and vehicle body. Butterworth-Heinemann, 2009.

[6] RILL, P.D.G. Vehicle Dynamics. University of applied sciences, 2007.

ScienceDirect, pp. 168 - 183, 2006.

[7] GENTA, G. Motor Vehicle Dynamics Modeling and Simulation. World Scientific, 2008.

[8] KULKARNI, Manish; SHIM, Taehyun; ZHANG, Yi. Shift dynamics and control of dualclutch transmissions. Mechanism and Machine Theory, v. 42, n. 2, p. 168-182, 2007.

[9] OLIVEIRA, Eude C. Modelagem e simulação de veículos elétricos e híbridos. 2005. Dissertação (Mestrado). Escola Politécnica da Universidade de São Paulo.

[10] ECKERT, J.J.; SANTICIOLLI, F.M.; CORRÊA, F.C.; SILVA, L.C.D.A.E. e DEDINI, F.G. Avaliação do desempenho em aclives de veículos híbridos. SIMEA XX Simpósio Internacional de Engenharia Automotiva, 2012.

[11] CORRÊA, F.C.; SILVA, L.C. e DEDINI, F.G. Fuzzy control for hybrid vehicle. 21st Brazilian Congress of Mechanical Engineering, v. 1, 9, 2011. 
[12] SERRAO, L., A.C.Z.; GUEZENNEC, Y. e RIZZONI, G. An aging model of ni-mh batteries for hybrid electric vehicles. IEEE Vehicle Power and Propulsion Conference (VPP05), v. 1, 78-85, 2005.

[13] ECOMODDER. Brake specific fuel consumption (BSFC) maps. Disponivel em: http://ecomodder.com

Acesso em: 20/0712.

[14] GM. Manual do proprietário Chevrolet Celta 2013. General Motors do Brasil Ltda., 2012.

[15] HAIM, Diego. Redução da inércia rotacional no projeto do trem de força. 2011. 